\title{
Kallikrein-kinin system in chronic subdural haematomas: its roles in vascular permeability and regulation of fibrinolysis and coagulation
}

\author{
Hirosuke Fujisawa, Haruhide Ito, Shiro Kashiwagi, Sadahiro Nomura, Mikiko Toyosawa
}

\begin{abstract}
The kallikrein-kinin system is closely related to both fibrinolysis and coagulation, and bradykinin-the end product of this system-is a powerful mediator which increases vascular permeability. In the present study, to test the hypothesis that the kallikrein-kinin system plays a part in the aetiology of chronic subdural haematomas, components of this system (prekallikrein, high molecular weight kininogen (HMW-kininogen), and bradykinin), and those of the fibrinolytic and coagulation systems were measured at 134 haematoma sites in 119 patients. The activities of prekallikrein and HMWkininogen in the haematomas were significantly lower than those in the plasma of the patients, and showed a parallel decrease. The bradykinin concentration in the haematomas was significantly higher than that in the plasma. These results indicate activation of the kallikrein-kinin system in chronic subdural haematomas. The activation of both fibrinolysis and coagulation was also shown, and there was a significant correlation between HMW-kininogen and plasminogen, fibrin/fibrinogen degradation products, or platelets in the haematomas. This suggests regulation of fibrinolysis and coagulation by the kallikrein-kinin system or mutual stimulation of these systems. In the outer membrane, perivascular haemorrhage, interstitial oedema, and leucocyte migration were evident microscopically, indicating an increase in vascular permeability. The protein concentration in the haematomas was significantly higher than that in the peripheral blood, indicating plasma exudation from the capillaries in the outer membrane. The activation of the kallikrein-kinin system, by increasing vascular permeability, may cause blood extravasation and plasma exudation from the capillaries into both the outer membrane and the haematoma cavity, resulting in enlargement of the haematoma.
\end{abstract}

$(\Im$ Neurol Neurosurg Psychiatry 1995;59:388-394)

Keywords: chronic subdural haematoma; kallikreinkinin system; bradykinin; aetiology
Although chronic subdural haematomas comprise a common disease in the field of neurosurgery, their aetiology is not yet fully understood. The haematoma cavity is encapsulated by the inner and outer membranes, blood vessels being absent in the first but abundant in the second. ${ }^{1}$ Thus it has been suggested that repetitive haemorrhage from the outer membrane causes progressive enlargement of a haematoma. ${ }^{23}$

The haematoma fluid contains low fibrinogen and high fibrin/fibrinogen degradation product concentrations, ${ }^{4}$ and a high amount of tissue type plasminogen activator has been found in both the haematoma fluid and the blood vessels in the outer membrane. ${ }^{56}$ Thus increased fibrinolysis in the outer membrane (local hyperfibrinolysis) has been suggested to be a main aetiological factor of chronic subdural haematomas. ${ }^{58}$ Indeed, repetitive haemorrhage from the outer membrane into the haematoma cavity, as the cause of haematoma enlargement, can be well explained by increased fibrinolysis. Some aspects which cannot be explained satisfactorily by increased fibrinolysis alone, however, remain unresolved-for example, (a) increased fibrinolysis alone cannot explain how the subdural membrane is produced; $(b)$ factors regulating the fibrinolytic activity during the course of development of chronic subdural haematomas have not been fully determined; $(c)$ in the outer membrane, perivascular haemorrhage, interstitial oedema, and leucocyte migration are seen microscopically. ${ }^{910}$ In cases of subdural hygromas which develop into chronic subdural haematomas, the $x$ ray absorption value of the subdural fluid on CT gradually increases. ${ }^{11-14}$ These findings seem to indicate an increase in vascular permeability of the outer membrane, although the factors responsible remain undetermined.

The kallikrein-kinin system consists basically of prekallikrein, kallikrein, high molecular weight kininogen (HMW-kininogen), and bradykinin (fig 1). Bradykinin-the end product of this system-is known to be a powerful mediator which increases vascular permeability and induces vasodilatation and leucocyte migration. ${ }^{15-17}$ Furthermore, through some common components, the kallikrein-kinin system is closely related not only to fibrinolysis but also to coagulation, which has also been suggested to play an important part in the origin and development of chronic subdural 


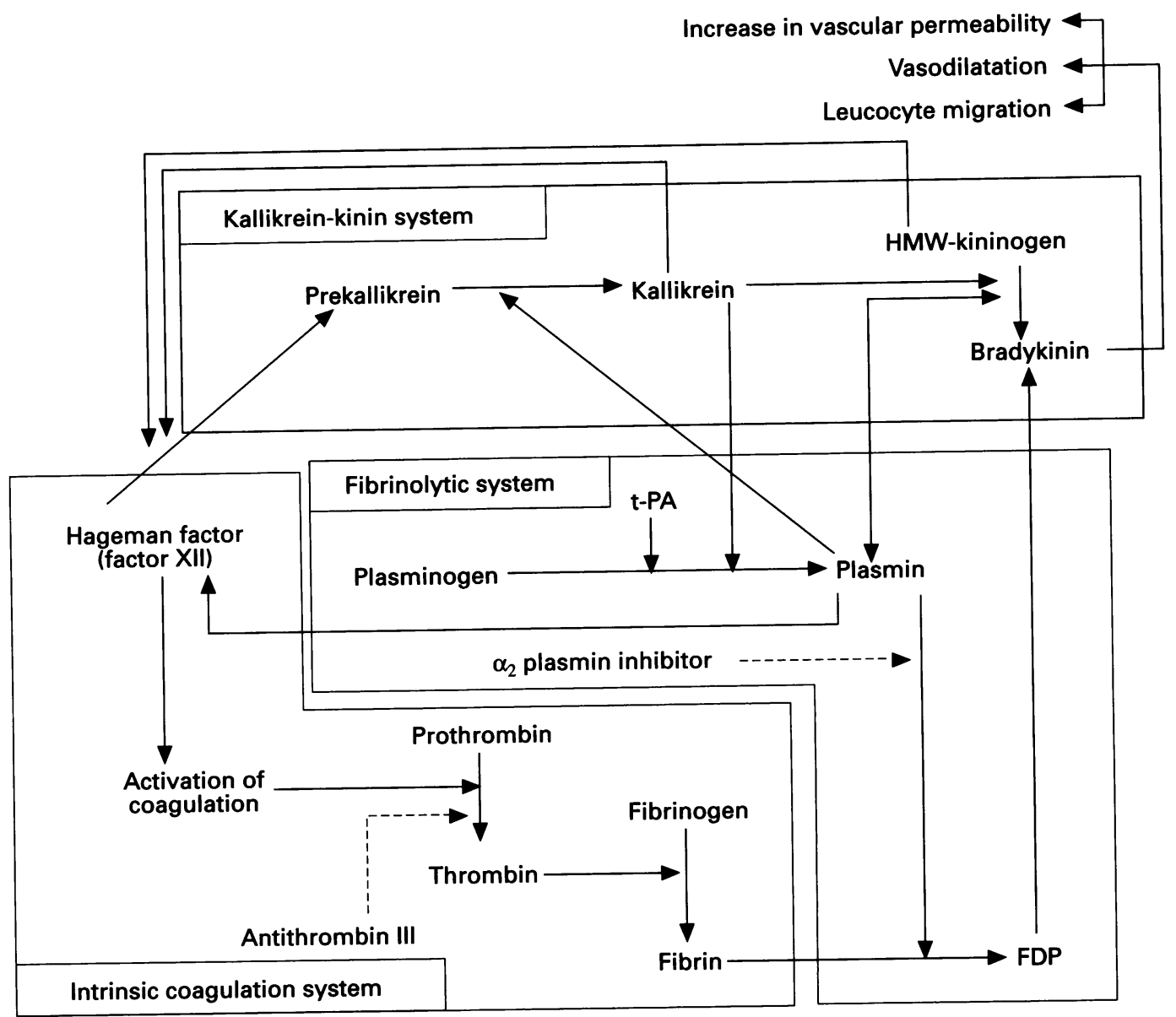

Figure 1 Functional diagram of the kallikrein-kinin system and its relation with the fibrinolytic and coagulation systems. HMW-kininogen $=$ high molecular weight kininogen; $t-P A=$ tissue-type plasminogen activator; FDP $=$ fibrin/fibrinogen degradation products. $\rightarrow=$ activation; $--\rightarrow=$ inhibition.

haematomas. ${ }^{8}$ In the present study, we measured the components of the kallikrein-kinin, fibrinolytic, and coagulation systems, and we discuss the possible contribution of the kallikrein-kinin system to the aetiology of chronic subdural haematomas.

\section{Materials and methods}

PATIENT POPULATION AND SAMPLING OF HAEMATOMAS AND MEMBRANES

Ninety male and 29 female patients with chronic subdural haematomas were studied. They ranged in age from 12 to 87 (mean 64.8) years, and had not received previous treatment for chronic subdural haematomas. One hundred and four of the patients had unilateral haematomas and 15 had bilateral haematomas. During surgery, the haematoma was aspirated by puncture through the dura mater with a disposable plastic syringe and the outer membrane attached to the dura mater was excised for histological examination. Peripheral blood samples were also taken from the patients.

HISTOLOGICAL EXAMINATION

A small piece of the dura mater along with the outer membrane was fixed in $10 \%$ formalin, processed routinely, and then embedded in paraffin. Thin sections $(4 \mu \mathrm{m})$ were cut, stained with haematoxylin and eosin, and examined by light microscopy.
MEASUREMENT OF THE KALLIKREIN-KININ SYSTEM

The three major components of the kallikreinkinin system were measured-namely, prekallikrein, HMW-kininogen, and bradykinin. For measurement of the prekallikrein and HMW-kininogen activities, haematoma samples were placed in siliconised vacuum tubes containing $3 \cdot 8 \%$ sodium citrate. For measurement of bradykinin, samples were placed in siliconised vacuum tubes containing aprotinin, soybean trypsin inhibitor, protamine sulphate, and disodium EDTA. All tubes were placed in a box filled with ice until centrifuged at $3000 \mathrm{rpm}$ for 10 minutes. Each supernatant was stored in a sealed polypropylene tube at $-70^{\circ} \mathrm{C}$ until analysis. The prekallikrein and HMW-kininogen activities were measured by the one stage activated partial thromboplastin time method, with prekallikrein-deficient plasma and HMWkininogen-deficient plasma respectively. ${ }^{18} 19$ These activities were expressed as percentages of those for normal plasma. Bradykinin was measured by radioimmunoassay. ${ }^{20}$

\section{MEASUREMENT OF THE FIBRINOLYTIC AND}

\section{COAGULATION SYSTEMS}

The major components of the fibrinolytic system-that is, fibrin/fibrinogen degradation products, tissue-type plasminogen activator, plasminogen, and $a 2$ plasmin inhibitor, were measured. Plasminogen and a2 plasmin 


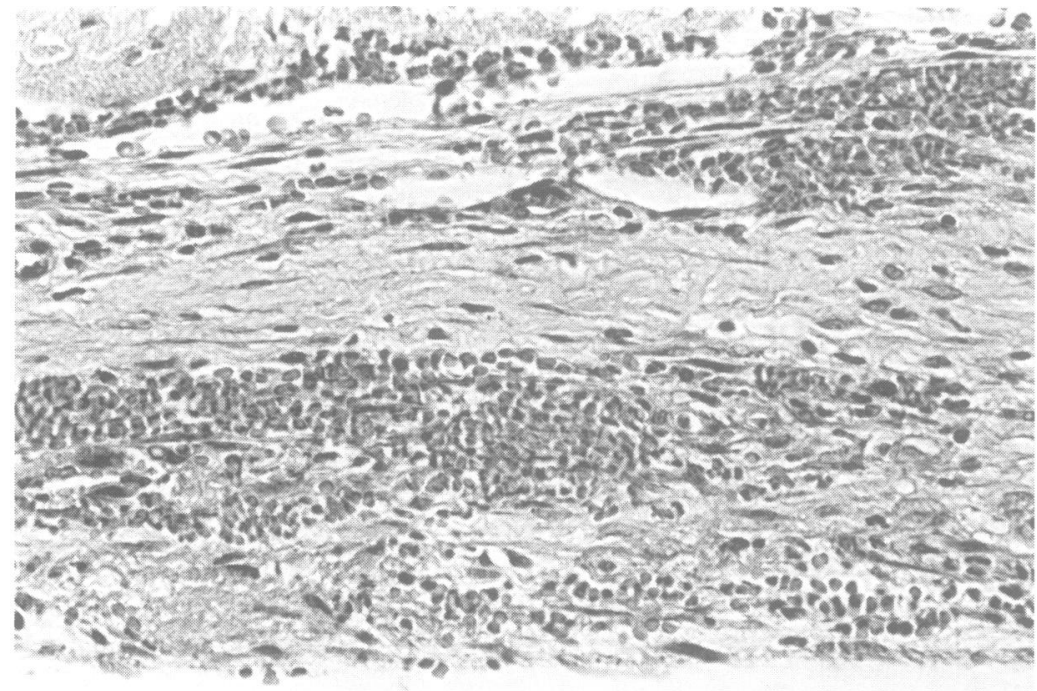

(A)

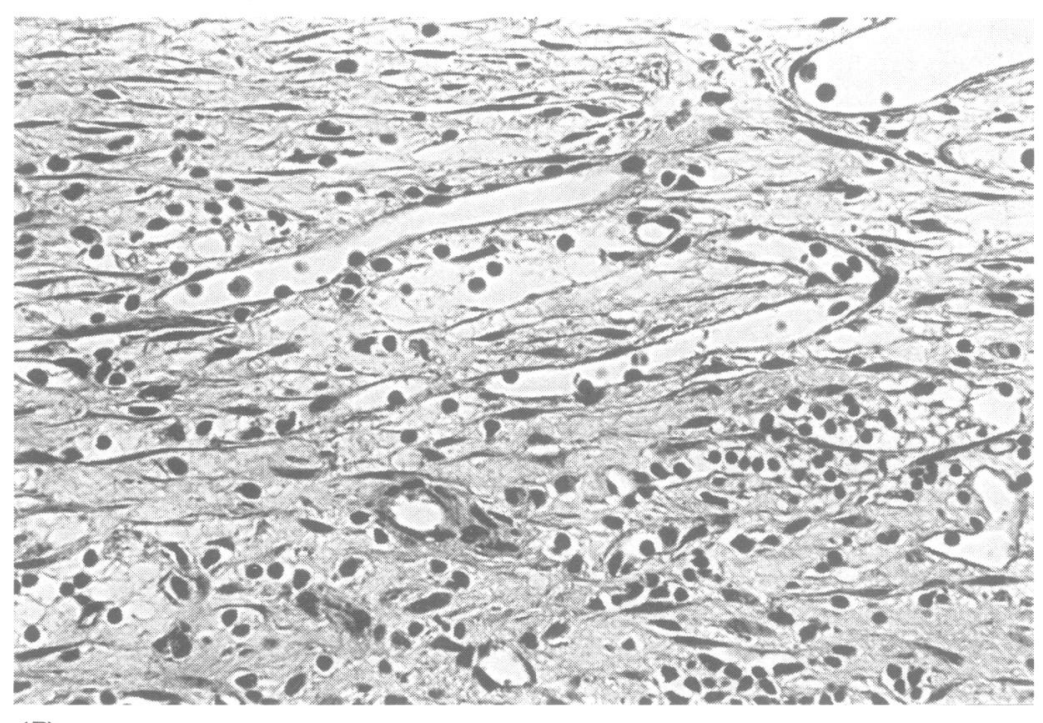

(B)

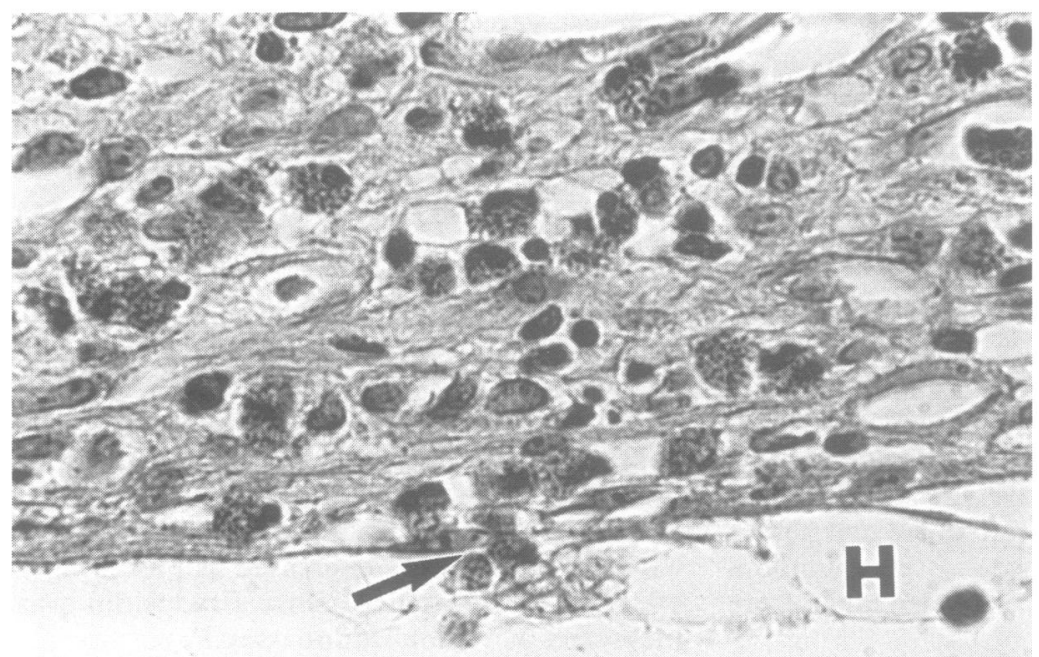

-

Figure 2 Histological findings in the outer membrane. (A) Massive perivascular haemorrhage (haematoxylin and eosin $\times 100$ ). (B) Interstitial oedema (haematoxylin and eosin $\times 100)$. (C) Migration of eosinophils. Capillaries can be seen close to the haematoma cavity. An eosinophil seems to be passing through the capillary into the haematoma cavity (arrow) (haematoxylin and eosin $\times 400) . H=$ haematoma cavity. inhibitor were measured by the synthetic chromogenic substrate method, fibrin/fibrinogen degradation products by the latex agglutination method, and tissue-type plasminogen activator by enzyme linked immunosorbent assay. ${ }^{521}$ The coagulation system in chronic subdural haematomas was investigated by measurement of platelets, fibrinogen, antithrombin III, prothrombin time, and activated partial thromboplastin time, and by means of the thrombo test and hepaplastin test. Fibrinogen was measured by the thrombin test, and antithrombin III by the synthetic chromogenic substrate method. The relations between the kallikrein-kinin, fibrinolytic, and coagulation systems were investigated.

\section{MEASUREMENT OF BLOOD CELLS AND THE} PROTEIN CONCENTRATION

White blood cells and erythrocytes, and the protein concentration in both a haematoma and peripheral blood were measured.

\section{STATISTICS}

Values are expressed as means (SEM). The statistical significance between two groups was assessed by unpaired Student's $t$ test. Bradykinin concentrations were analysed by the Wilcoxon signed rank test. Differences among three groups were tested by one way analysis of variance (ANOVA), followed by Scheffé's $F$ test for multiple comparisons. Correlations between different variables were examined by Pearson's linear regression.

\section{Results}

HISTOLOGICAL FINDINGS IN THE OUTER MEMBRANE

Morphologically, the outer membranes comprised granulation tissue consisting of collagen fibrils, fibroblasts, and abundant capillaries (macrocapillaries or sinusoids). Perivascular haemorrhage, interstitial oedema, and leucocyte migration were often seen (fig 2). Some of the capillaries were in direct contact with the haematoma cavity, and some white blood cells and erythrocytes seemed to be passing through the capillaries into the haematoma cavity (fig 2C). Although the migration of only eosinophils is shown in fig 2 , neutrophils, lymphocytes, haemosiderin containing macrophages, and plasma cells were also present in some specimens. Among leucocytes, eosinophils were present most often and were most easily identified on light microscopy. To compare the amounts of leucocytes in the outer membrane and a haematoma, eosinophils in the outer membrane were counted in 24 membrane specimens at a magnification of $\times 40$, and then the outer membranes were divided into three groups according to the number of eosinophils present: no eosinophils $(n=8)$; a few eosinophils (cell count $\leqslant 60 ; n=5$ ); many eosinophils (cell count $\geqslant 100 ; n=11$ ).

THE KALLIKREIN-KININ SYSTEM

Prekallikrein activity in the haematomas was $54.6(2 \cdot 6) \%$, significantly lower than that in the plasma of the patients $(79 \cdot 4(2 \cdot 7) \%$; fig 

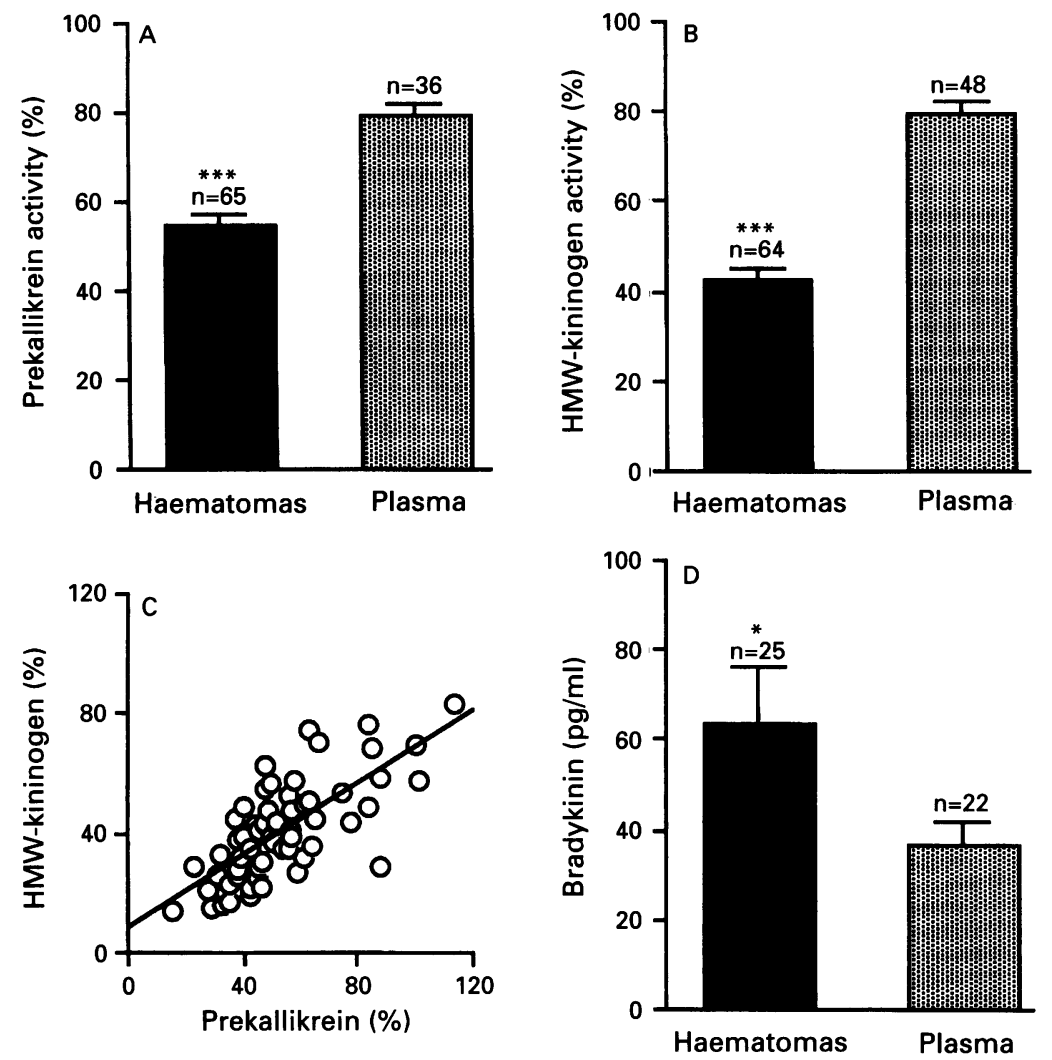

Figure 3 (A) Prekallikrein activities in the haematomas and plasma ${ }^{\star * \star} P<0.001$; Student's $t$ test). (B) HMW-kininogen activities in the haematomas and plasma $(\star \star \star P<0.001$; Student's $t$ test). (C) Correlation between prekallikrein and HMWkininogen activities in the haematomas (62 paired observations. $r=0.72, P<0.0001$; Pearson's linear regression). (D) Bradykinin concentrations in the haematomas and plasma ( ${ }^{*} P<0.05$; Wilcoxon signed rank test).
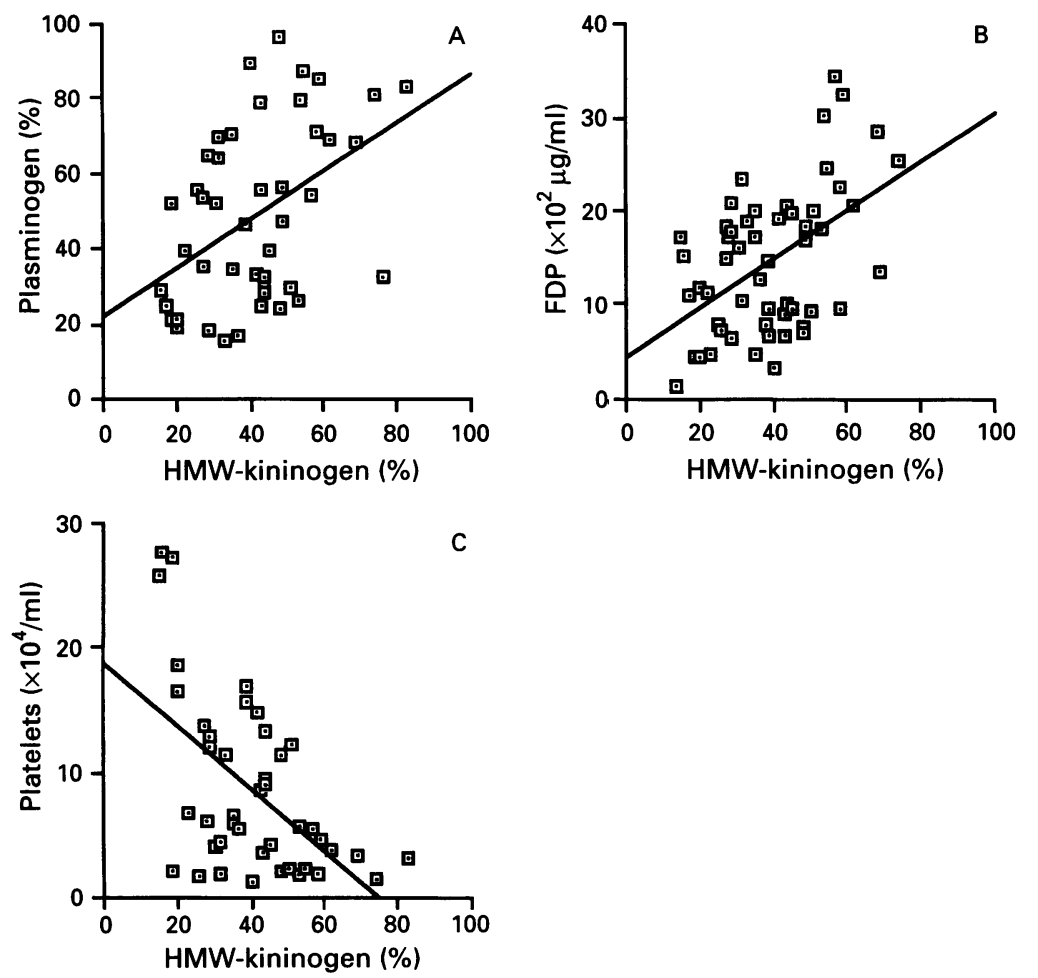

Figure 4 (A) Correlation between HMW-kininogen and plasminogen in the haematomas (46 paired observations. $r=0.45, P<0.005$; Pearson's linear regression). (B) Correlation between HMW-kininogen and FDP in the haematomas (54 paired observations $r=0.50, P<0.0001$ by Pearson's linear regression). (C) Correlation between HMW-kininogen and platelets in the haematomas (43 paired observations. $r=-0.56, P<0.0001$ by Pearson's linear regression).
3A). HMW-kininogen activity in the haematomas was $42 \cdot 4(2 \cdot 4) \%$, significantly lower than that in the patients' plasma $(79 \cdot 2$ $(3 \cdot 2) \%$; fig 3B). Prekallikrein and HMWkininogen activities in the haematomas showed a parallel decrease and a significant correlation (fig 3C). The bradykinin concentration in the haematomas $(63.9(12 \cdot 1 \mathrm{pg} / \mathrm{ml}))$ was significantly higher than that in the plasma $(36.4(5 \cdot 6 \mathrm{pg} / \mathrm{ml}$; fig $3 \mathrm{D}))$.

\section{FIBRINOLYSIS AND COAGULATION}

The plasminogen and $a 2$ plasmin inhibitor concentrations in the haematomas were significantly lower than those in the peripheral blood of the patients (table 1). The fibrin/ fibrinogen degradation products and tissuetype plasminogen activator concentrations in the haematomas were significantly higher than those in the peripheral blood. As to the relation between the kallikrein-kinin and fibrinolytic systems, there was a significant correlation between $\mathrm{HMW}$-kininogen and plasminogen or fibrin/fibrinogen degradation products (fig 4A, 4B).

The haematomas contained an extremely low level of fibrinogen (table 1). Platelet count and antithrombin III in the haematomas were significantly lower than those in the peripheral blood. Prothrombin time and activated partial thromboplastin time in the haematomas were significantly prolonged, and results of the thrombo test and hepaplastin test for the haematomas gave lower values than for peripheral blood. There was a significant correlation between HMW-kininogen and platelets (fig 4C).

\section{BLOOD CELIS AND PROTEIN CONCENTRATIONS}

The haematomas contained white blood cells and erythrocytes (table 2). The number of eosinophils in the haematomas increased in parallel with the number in the outer membrane (table 3 ).

The protein concentration in the peripheral blood of the patients was $6 \cdot 3(0 \cdot 1 \mathrm{~g} / \mathrm{dl})$, being within the normal range. By contrast, the protein concentration in the haematomas was 8.4 $(0.4 \mathrm{~g} / \mathrm{dl})$, significantly higher than that in the peripheral blood (table 2).

\section{Discussion}

ACTIVATION OF THE KALLIKREIN-KININ SYSTEM IN CHRONIC SUBDURAL HAEMATOMAS

The kallikrein-kinin system consists of prekallikrein, kallikrein, HMW-kininogen, and bradykinin (fig 1). Prekallikrein is present in plasma as an inactive precursor and is transformed into kallikrein by activated coagulation factor XII (Hageman factor). There are two types of kininogen in human plasma; HMWkininogen and low molecular weight kininogen. Kallikrein prefers HMW-kininogen as a substrate, converting it to bradykinin. ${ }^{15}$ Activation of the kallikrein-kinin system is an extremely rapid process, ${ }^{15}$ and the half life of bradykinin is very short (about 17 seconds) due to the action of kininases. ${ }^{22}$ If reduction of both prekallikrein and HMW-kininogen 
Table 1 Components of the fibrinolytic and coagulation systems

\begin{tabular}{lcc}
\hline & Haematomas & \multicolumn{1}{c}{ Peripheral blood } \\
\hline FDP $(\mu \mathrm{g} / \mathrm{ml})$ & $1078(72)^{\star \star \star}(\mathrm{n}=114)$ & $7 \cdot 0(0 \cdot 8)(\mathrm{n}=48)$ \\
Plasminogen $(\%)$ & $50 \cdot 1(3 \cdot 4)^{\star \star \star}(\mathrm{n}=51)$ & $84 \cdot 7(4 \cdot 1)(\mathrm{n}=41)$ \\
t-PA $(\mathrm{ng} / \mathrm{ml})$ & $10 \cdot 1(0 \cdot 6)^{\star \star \star}(\mathrm{n}=134)$ & $3 \cdot 7(0 \cdot 2)(\mathrm{n}=79)$ \\
$\alpha 2$ PI $(\%)$ & $30 \cdot 0(2 \cdot 5)^{\star \star \star}(\mathrm{n}=50)$ & $92 \cdot 3(3 \cdot 0)(\mathrm{n}=41)$ \\
Platelets $\left(\times 10^{4} / \mathrm{ml}\right)$ & $9 \cdot 9(1 \cdot 5)^{\star \star \star}(\mathrm{n}=48)$ & $25 \cdot 0(1 \cdot 6)(\mathrm{n}=48)$ \\
Fibrinogen $(\mathrm{mg} / \mathrm{dl})$ & $10 \cdot 4(2 \cdot 8)^{\star \star \star}(\mathrm{n}=53)$ & $278 \cdot 7(18 \cdot 4)(\mathrm{n}=45)$ \\
PT (s) & $189 \cdot 3(1 \cdot 5)^{\star \star \star}(\mathrm{n}=53)$ & $12 \cdot 5(0 \cdot 2)(\mathrm{n}=45)$ \\
APTT (s) & $195 \cdot 9(2 \cdot 9)^{\star \star \star}(\mathrm{n}=54)$ & $35 \cdot 0(1 \cdot 0)(\mathrm{n}=45)$ \\
Thrombo test $(\%)$ & $25 \cdot 1(2 \cdot 1)^{\star \star \star}(\mathrm{n}=30)$ & $66 \cdot 1(3 \cdot 9)(\mathrm{n}=27)$ \\
Hepaplastin test (\%) & $24 \cdot 9(2 \cdot 0)^{\star \star \star}(\mathrm{n}=53)$ & $110 \cdot 1(2 \cdot 5)(\mathrm{n}=40)$ \\
AT III (\%) & $42 \cdot 6(1 \cdot 9)^{\star \star \star}(\mathrm{n}=49)$ & $99 \cdot 7(2 \cdot 4)(\mathrm{n}=41)$ \\
\hline
\end{tabular}

FDP = fibrin/fibrinogen degradation products; $\mathrm{t}-\mathrm{PA}=$ tissue-type plasminogen activator; $\alpha 2 \mathrm{PI}=$ $\alpha 2$ plasmin inhibitor; $\mathrm{PT}=$ prothrombin time; APTT = activated partial thromboplastin time; AT III $=$ antithrombin III. ${ }^{\star \star \star} \mathrm{P}<0.001 v$ peripheral blood (Student's $t$ test).

Table 2 Blood cells and protein concentrations

\begin{tabular}{lcc}
\hline & Haematomas & Peripheral blood \\
\hline White blood cells $(/ \mathrm{ml})$ & $5781(1068)(\mathrm{n}=52)$ & $6994(361)(\mathrm{n}=48)$ \\
Erythrocytes $\left(\times 10^{4} / \mathrm{ml}\right)$ & $303(18)^{\star \star \star}(\mathrm{n}=53)$ & $383(7)(\mathrm{n}=48)$ \\
Protein $(\mathrm{g} / \mathrm{dl})$ & $8.4(0.4)^{\star \star \star}(\mathrm{n}=61)$ & $6.3(0 \cdot 1)(\mathrm{n}=39)$ \\
\hline$\star \star \star \mathrm{P}<0.001 v$ peripheral blood (Student's $t$ test) &
\end{tabular}

$\star \star \star P<0.001 v$ peripheral blood (Student's $t$ test).

Table 3 Eosinophils in the outer membrane and haematomas

\begin{tabular}{lc}
\hline Outer membrane & Haematomas $(\mid m l)$ \\
\hline Eosinophils: & $77(29)(\mathrm{n}=8)$ \\
None & $502(357)(\mathrm{n}=5)$ \\
Few (cell count $\leqslant 60)$ & $5202(1246)(\mathrm{n}=11)$ \\
Many (cell count $\geqslant 100)$ & ${ }^{\star} \mathrm{P}<0.05, \star \star \star \mathrm{P}<0.001$ by ANOVA, followed by Scheffé's test for multiple comparisons.
\end{tabular}

occurs this could be regarded as indirect proof of activation of this system. The prekallikrein and HMW-kininogen activities in normal plasma are $102(23) \%^{23}$ and $99(25) \%^{18}$ respectively. In the present study, plasma prekallikrein and HMW-kininogen activities in the patients remained within the normal range, whereas the corresponding activities in the haematomas were significantly lower and showed a parallel decrease. Furthermore, despite its short half life, the concentration of bradykinin in the haematomas was significantly higher than that in the plasma. These results indicate that local activation of the kallikrein-kinin system occurs in chronic subdural haematomas.

\section{INCREASE OF VASCULAR PERMEABILITY IN} CHRONIC SUBDURAL HAEMATOMAS

The haematoma fluid contains white blood cells and erythrocytes. Ito et $a l^{3}$ demonstrated daily haemorrhage from the outer membrane into the haematoma cavity by the chromium51 labelled erythrocyte infusion method. The present study disclosed a parallel increase of eosinophils in both the outer membrane and the haematomas. Thus the blood cells in the haematomas must extravasate from the capillaries in the outer membrane, and it may be due to an increase in vascular permeability. In the outer membrane, perivascular haemorrhage, interstitial oedema, and leucocyte migration, which also indicate an increase in vascular permeability, are often evident microscopically. Ultrastructural studies of the outer membrane have shown gaps between capillary endothelial cells at the sites of leakage of erythrocytes and plasma, which are observed microscopically as perivascular haemorrhage and interstitial oedema respectively. ${ }^{10}$ These endothelial gaps are known to be anatomical substrata for the increase in vascular permeability. ${ }^{15}$

The protein concentration in the haematomas was significantly higher than that in the peripheral blood, and similar to that in the fluid exudate of inflamed tissue. It has been reported that chronic subdural haematomas show changes in density on CT and in signal intensity on MRI, which has been attributed to rebleeding into the haematoma cavity or a chemical change in haemoglobin. ${ }^{24-27}$ Although bleeding or haemolysis may be partly responsible for the high protein concentration in the haematoma, we speculate that plasma exudation from the capillaries in the outer membrane due to an increase in vascular permeability may also play a part. For example, in cases of subdural hygromas, the $x$ ray absorption values on CT or signal intensity on T1 weighted MRI of the subdural fluid gradually increase. ${ }^{11-14}$ Subdural hygromas contain a high concentration of protein, ${ }^{1314}$ and histological examinations have shown that they have the same kind of subdural membrane as that seen in chronic subdural haematomas. ${ }^{28}$ Fluid exudation due to increased vascular permeability of the membrane may therefore play an important part in creating the high protein concentration and in increasing the volume of subdural hygromas, and the same may be the case in chronic subdural haematomas. The question arises, however, as to what causes the increase in vascular permeability.

Many factors have been reported to increase vascular permeability in reparative or inflammatory tissue ${ }^{15}$-for example, bradykinin, histamine, serotonin, and prostaglandins. As the outer membrane of chronic subdural haematomas is a kind of reparative tissue, these factors could be activated. Among these factors, bradykinin is known to be the most powerful mediator for increasing vascular permeability. For example, its effect on vascular permeability is at least 20 times as strong as that of histamine or prostaglandins. ${ }^{29}$ Although serotonin induces effects similar to histamine in rodents, its role in humans has not been established. ${ }^{30}$ Thus we speculate that bradykinin generated by activation of the kallikrein-kinin system is the main factor responsible for increasing vascular permeability in chronic subdural haematomas. An important role of the kallikrein-kinin system in the pathogeneses of various pathological conditions through increasing vascular permeability has also been reported. ${ }^{151-33}$

RELATION OF THE KALLIKREIN-KININ SYSTEM WITH FIBRINOLYSIS AND COAGULATION, AND PUTATIVE AETIOLOGY OF CHRONIC SUBDURAL HAEMATOMAS

The present study demonstrated low plasminogen and $a 2$ plasmin inhibitor, and high fibrin/fibrinogen degradation products and 
A

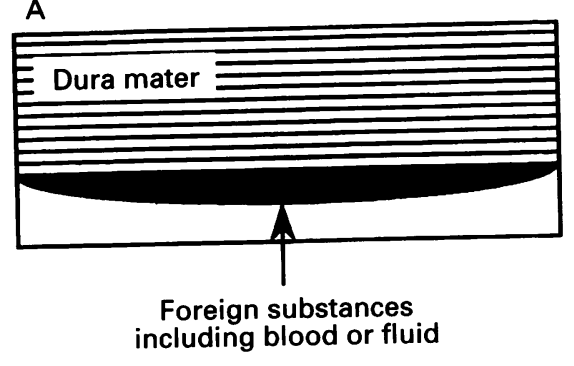

including blood or fluid

C
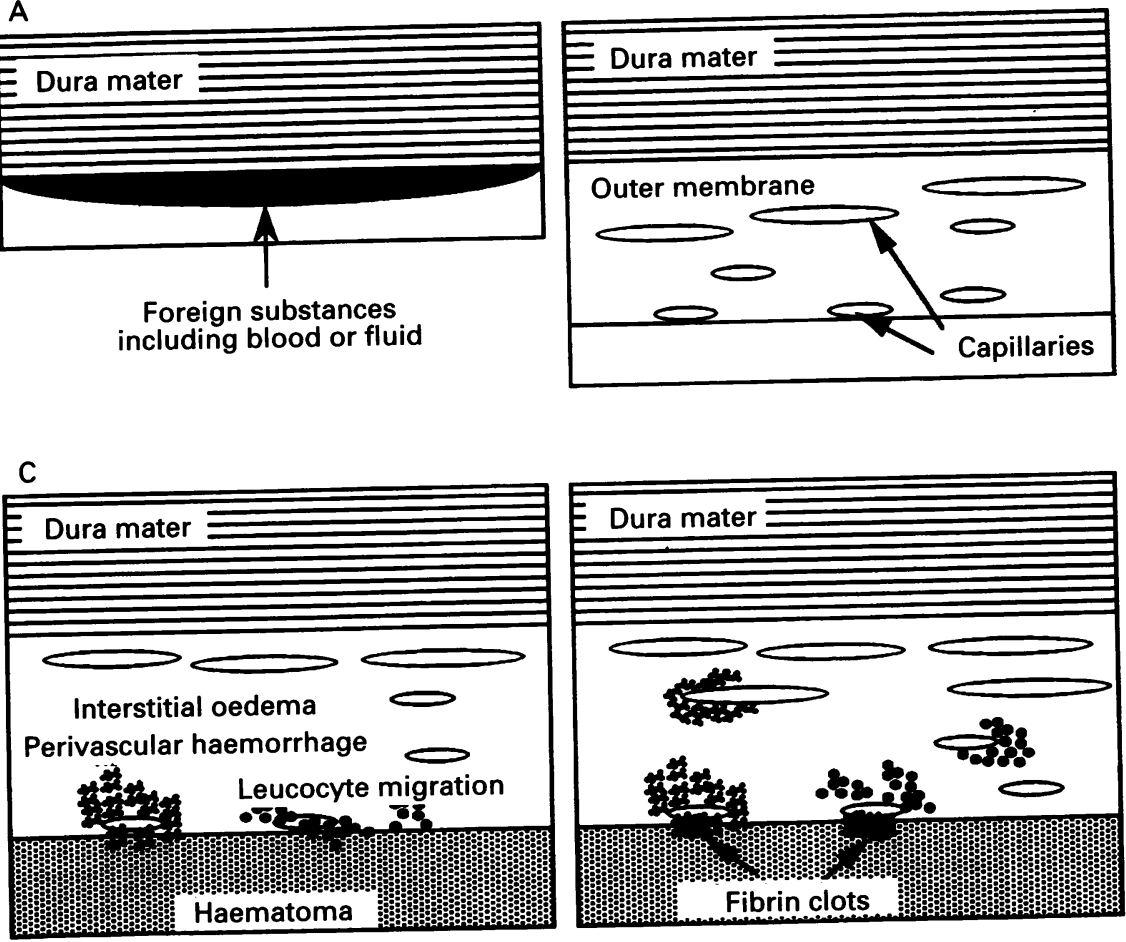

B
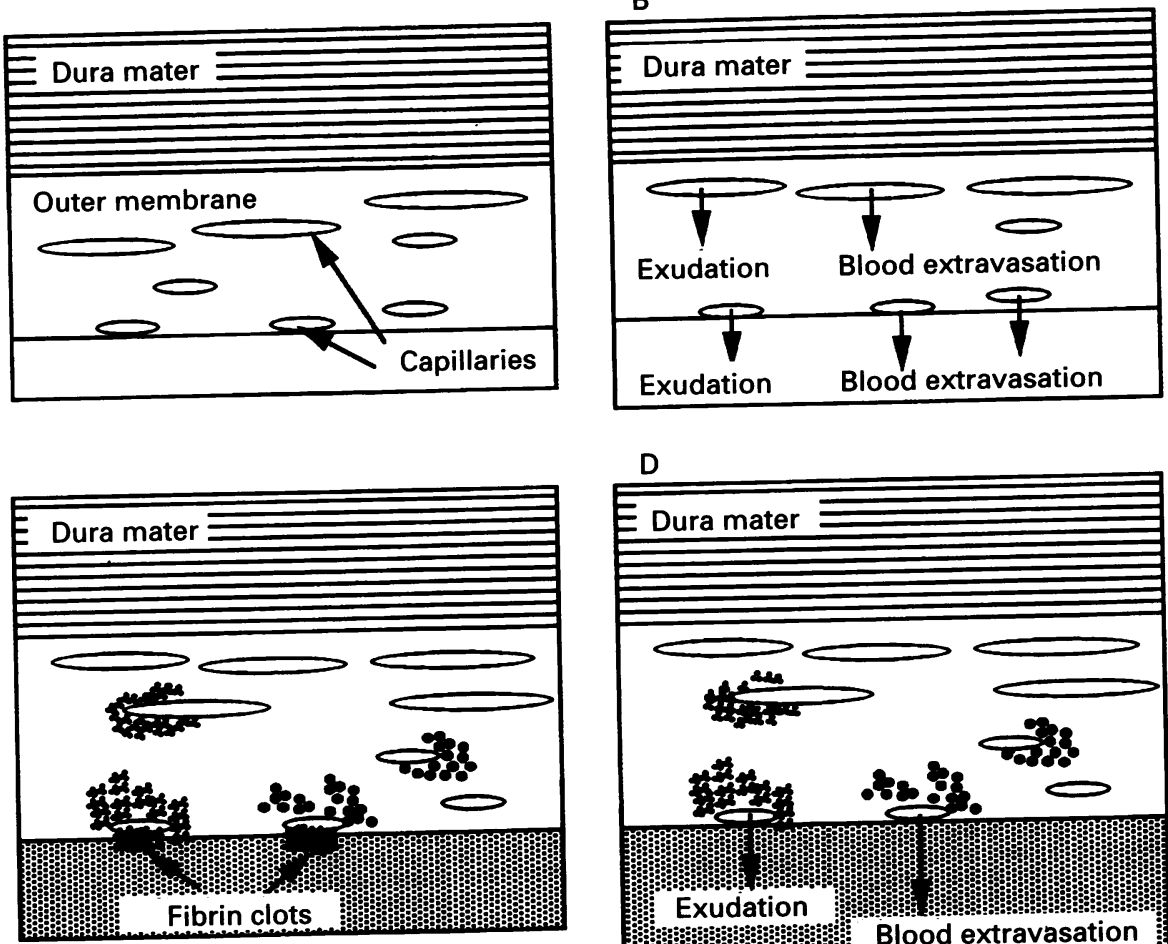

D

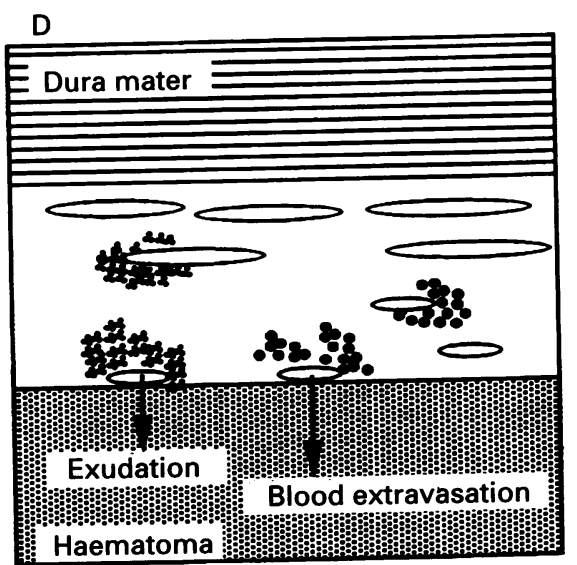

Figure 5 Putative aetiology of chronic subdural haematomas. (A) Formation of the subdural membrane. (B) Blood extravasation and plasma exudation. (C) Haemostasis. (D) Rebleeding.

tissue-type plasminogen activator concentrations in the haematomas, providing evidence of activation of the fibrinolytic system in chronic subdural haematomas. As mentioned earlier, it is now generally accepted that increased fibrinolysis is the most important aetiological factor in chronic subdural haematomas. Ito et $a l^{5}$ suggested that regulation of fibrinolysis determines the course of chronic subdural haematomas; local hyperfibrinolysis prevents haemostasis and causes rebleeding into the haematoma cavity. The present study also showed activation of the coagulation system in chronic subdural haematomas: a reduction in antithrombin III indicates increased thrombin activity, and prolonged prothrombin time and activated partial thromboplastin time, and low thrombo test and hepaplastin test values indicate consumptive reduction of coagulation factors II, $\mathrm{V}$, and $\mathrm{X}$. Kawakami et $a l^{8}$ suggested that excessive activation of coagulation as well as hyperfibrinolysis caused the formation of the outer membrane and the development of chronic subdural haematomas. Factors that regulate fibrinolysis and coagulation, however, during the course of chronic subdural haematoma development have not been fully determined. The kallikrein-kinin system is closely related to both the fibrinolytic and intrinsic coagulation systems through some common components (fig 1): Factor XII converts prekallikrein to kallikrein, and is activated by plasmin and kallikrein; ${ }^{15}$ HMW-kininogen is essential for the surface activation of factor XII; ${ }^{34}$ fragments released from HMW-kininogen prolong the clotting time and inhibit the formation of active Hageman factor; ${ }^{34}$ and kallikrein converts plasminogen into plasmin, ${ }^{16}$ plasmin converts HMW-kininogen to bradykinin, ${ }^{163536}$ and fibrin/fibrinogen degradation products enhance the action of bradykinin. ${ }^{37} 38$ In the present study, a significant correlation was found between HMW-kininogen and plasminogen, fibrin/fibrinogen degradation products, or platelets, suggesting possible regulation of fibrinolysis and coagulation by the kallikrein-kinin system or mutual stimulation of these systems in chronic subdural haematomas.

Figure 5 illustrates the putative aetiology of chronic subdural haematomas. Morphologically, the outer membrane is composed of granulation tissue, and thus some reactive responses may occur in the subdural space during the early stage, leading to the production of the highly vascularised outer membrane (fig 5A). This view is supported by the fact that chronic subdural haematomas occasionally develop from acute subdural haematomas. ${ }^{39} 40$ In these cases, fibroblasts and capillaries proliferate in the fibrin clots to form the subdural granulation tissue. Fibrin is known to be produced not only in extravasated blood but also in fluid exudates, and forms a matrix for migrating fibroblasts. Thus any foreign substance in the subdural space, as well as small amounts of subdural haemorrhage or fluid, may stimulate the formation of the membrane. Then, blood extravasation, plasma exudation, and leucocyte migration into both the membrane and the haematoma cavity may occur due to an increase in vascular permeability (fig $5 B$ ). This 
increase may be caused by the kallikrein-kinin system as discussed earlier. Then platelets may aggregate and fibrin clots may be formed in the endothelial gaps of capillaries, some of which are in direct contact with the haematoma cavity. ${ }^{10}$ The clots may be easily broken down, however, due to local hyperfibrinolysis (fig $5 \mathrm{C}$ ). This view is supported by the fact that most of the fibrin/fibrinogen degradation products in the haematoma fluid are derived from degradation of fibrin (not fibrinogen). ${ }^{41}$ Bleeding and plasma exudation from the capillaries then recur, resulting in enlargement of the haematoma (fig 5D).

In the present study, showing the activation of the kallikrein-kinin system and the close relation of this system with fibrinolysis and coagulation, we have suggested that the kallikrein-kinin system plays an important part in the aetiology of chronic subdural haematomas. There may be some controversy, however, as to whether the activation of this system in chronic subdural haematomas is merely an epiphenomenon or whether this activation is sufficient to exert important biological effects in chronic subdural haematomas. Further pharmacological investigations involving specific inhibitors (for example, bradykinin antagonists or kallikrein blockers) will help to resolve these issues and will be of interest for both experimental and clinical application.

1 Sato S, Suzuki J. Ultrastructural observations of the capsule of chronic subdural hematoma in various clinical stages. $\mathcal{F}$ Neurosurg 1975;43:569-78.

2 Ito $\mathrm{H}$, Yamamoto $\mathrm{S}$, Komai $\mathrm{T}$, Mizukoshi $\mathrm{H}$. Role of hyperfibrinolysis in the etiology of chronic subdural hematoma. F Neurosurg 1976;45:26-31.

3 Ito $\mathrm{H}$, Yamamoto S, Saito K, Ikeda K, Hisada K. Quantitative estimation of hemorrhage in chronic subdural hematoma using the ${ }^{51} \mathrm{Cr}$ erythrocyte labeling method. $尹$ Neurosurg 1987;66:862-4

4 Ito $\mathrm{H}$, Komai $\mathrm{T}$, Yamamoto $\mathrm{S}$. Fibrin and fibrinogen degradation products in chronic subdural hematoma. Neurol Med Chir (Tokyo) 1975;15:51-5.

5 Ito $\mathrm{H}$, Saito $\mathrm{K}$, Yamamoto $\mathrm{S}$, Hasegawa T. Tissue-type plasminogen activator in the chronic subdural hematoma. Surg Neurol 1988;30:175-9.

6 Fujisawa H, Ito H, Saito K, Ikeda K, Nitta H, Yamashita J. Immunohistochemical localization of tissue-type plasminogen activator in the lining wall of chronic subdural hematoma. Surg Neurol 1991;35:441-5.

7 Weir B, Gordon P. Factors affecting coagulation: fibrinolysis in chronic subdural fluid collections. $\mathcal{F}$ Neurosurg 1983;58:242-5.

8 Kawakami Y, Chikama M, Tamiya T, Shimamura Y Coagulation and fibrinolysis in chronic subdural hematoma. Neurosurgery 1989;25:25-9.

9 Friede RL, Schachenmayr W. The origin of subdural neomembranes: II. Fine structure of neomembranes. $\mathrm{Am}$ f Pathol 1978;92:69-84.

10 Yamashima T, Yamamoto S, Friede RL. The role of endothelial gap junctions in the enlargement of chronic subdural hematomas. F Neurosurg 1983;59:298-303.

11 Miyazaki S, Ohmori H, Kanazawa Y, Munekata $\mathrm{K}$ Fukushima H, Kamata $K$. The pathogenesis of chronic subdural hematoma: sequential study with computerized tomoraphy. Neurol Med Chir (Tokyo) 1980;20:875-81.

12 Ohno K, Suzuki R, Masaoka H, Matsushima Y, Inaba Y, Monma S. Role of traumatic subdural fluid collection in developing process of chronic subdural hematoma. Bull Tokyo Med Dent Univ 1986;33:99-106.

13 St John JN, Dila C. Traumatic subdural hygroma in adults. Neurosurgery 1981;9:621-6.
14 Stone JL, Lang RGR, Sugar O, Moody RA. Traumatic subdural hygroma. Neurosurgery 1981;8:542-50.

15 Marceau F, Lussier A, Regoli D, Giroud JP. Pharmacology of kinins: their relevance to tissue injury and inflammation. Gen Pharmacol 1983;14:209-29.

16 Ratnoff OD. Increased vascular permeability induced by human plasmin. $\mathcal{F}$ Exp Med 1965;122:905-21

17 Ratnoff OD. Mediators of inflammation. $\mathcal{f}$ Allergy Clin Immunol 1976;58:438-46.

18 Saito H, Goldsmith G, Waldmann R. Fitzgerald factor (high molecular weight kininogen) clotting activity in human plasma in health and disease in various animal plasmas. Blood 1976;48:941-7.

19 Saito H, Poon MC, Vicic W, Goldsmith GH Jr, Menitove JE. Human plasma prekallikrein (Fletcher factor) clotting activity and antigen in health and disease. $f$ Lab Clin Med 1978;92:84-95.

20 Ando T, Shimamoto K, Nakahashi Y, Nishitani T, Hosoda $\mathrm{S}$, Ishida $\mathrm{H}$, et al. Blood kinin measurement by sensitive kinin radioimmunoassay and its clinical application. In: Fritz H, Dietze G, Fiedler F, Haberland GL, eds. Recent progress on kinins. International Conference $\ll$ Kinin
Munich $\gg$. Munich: Birkhäuser Verlag, 1982:222-6.

21 Bergsdorf $N$, Nilsson T, Wallen P. An enzyme linked immunosorbent assay for determination of tissue plasminogen activator applied to patients with thromboem bolic disease. Thromb Haemost 1983;50:740-4.

22 Vane JR. The release and fate of vaso-active hormones in the circulation. Br $¥$ Pharmacol 1969;35:209-42.

23 Hathaway WE, Belhasen LP, Hathaway HS. Evidence for a new plasma thromboplastin factor: I. Case report, a new plasma thromboplastin factor: I. Case report, Blood 1965;26:521-32.

24 Karasawa H, Tomita S, Suzuki S. Chronic subdural hematomas: time-density curve and iodine concentration in enhanced CT. Neuroradiology 1987;29:36-9.

25 Naganuma H, Fukamachi A, Kawakami M, Misumi S. Spontaneous resolution of chronic subdural hematomas. Neurosurgery 1986;19:794-8.

26 Takahashi Y, Mikami J, Ueda M, Ito K, Sato H, Matsuoka $\mathrm{T}$, et al. Analysis of chronic subdural hematoma based on CT (part III): clinical stage classification based on CT findings. Neurol Med Chir (Tokyo) 1984;24:607-14.

27 Hosoda K, Tamaki N, Masumura M, Matsumoto S, Maeda F. Magnetic resonance images of chronic subdural hematomas. $₹$ Neurosurg 1987;67:677-83.

28 Hasegawa M, Yamashima T, Yamashita J, Suzuki $M$ Shimada S. Traumatic subdural hygroma: pathology and Shimada S. Traumatic subdural hygroma: pathology and meningeal enhancement on marosurgery 1992;31:580-5.

29 Ikeda K, Tanaka K, Katori M. Potentiation of bradykinininduced vascular permeability increase by prostaglandin $\mathrm{E} 2$ and arachidonic acid in rabbit skin. Prostaglandins 1975;10:747-58.

30 Robbins SL, Angell M, Kumar V. Inflammation and repair. In: Robbins SL, Angell M, Kumar V, eds. Basic pathol$o g y$. Tokyo: Igaku-shoin/Saunders, 1981:28-61.

31 Melmon KL, Webster ME, Goldfinger SE, Seegmiller JE. The presence of a kinin in inflammatory synovial effusion from arthritides of varying etiologies. Arthritis Rheum 1967;10:13-20.

32 Oh-ishi S, Hayashi I, Hayashi M, Yamaki K, Yamasu A, Nakano $T$, et al. Evidence for a role of the plasma kallikrein-kinin system in acute inflammation: reduced exudation during carrageenin- and kaolin-pleurisies in kininogen-deficient rats. Agents Actions 1986;18:451-4.

33 Ryan JW, Moffat JG, Thompson AG. Role of bradykinin in the development of acute pancreatitis. Nature 1964;204: 1212-3.

34 Oh-ishi S, Katori M, Han YN, Iwanaga S, Kato H, Suzuki $\mathrm{T}$. Possible physiological role of new peptide fragments released from bovine high molecular weight kininogen by plasma kallikrein. Biochem Pharmacol 1977;26:115-20.

35 Back N, Steger B. Activation of bovine bradykininogen by human plasmin. Life Sci 1965;4:153-7.

36 Lewis GP. Formation of plasma kinins by plasmin. $f$ Physiol 1958;140:285-300.

37 Buluk K, Malofiejew $M$. The pharmacological properties of fibrinogen degradation products. Br F Pharmacol 1969; 35:79-89.

38 Malofiejew $M$. The biological and pharmacological properties of some fibrinogen degradation products. Scand $\mathcal{F}$ Haematol 1971;13(Suppl):79-89.

39 Taguchi Y, Yamaguchi Y, Hayashi T, Sekino H. Evolution from acute subdural hematomas to chronic subdural hematoma. In: Nakamura N, Hashimoto T, Yasue $M$, eds. Recent advances in neurotraumatology. Tokyo: Springer-Verlag, 1993:84-7

40 Yoshimasu N, Tamura A, Wakai S, Wakai S, Yoshimoto S. Evolution from acute subdural hemorrhage to chronic subdural hematoma: observation of subdural hematoma by computerized tomography. Neurological Surgery (Tokyo) 1981;9:1025-31.

41 Saito K, Ito H, Fujisawa H, Ikeda K, Yamamoto S. FDP subfraction in the supernatant of the chronic subdural hematoma. Neurotraumatology (Tokyo) 1987;10:186-9. 